\title{
Reactivity of Antibodies in Human Serum with Antigens of an Enteropathogenic Bovine Coronavirus
}

\author{
J. Storz ${ }^{1}$ and R. Rott ${ }^{2}$ \\ 1 Department of Microbiology, Colorado State University, Fort Collins, CO 80523, USA \\ 2 Institut für Virologie, Justus-Liebig-Universität Giessen, Giessen, Federal Republic of Germany
}

\begin{abstract}
Antibodies in human serum against an enteropathogenic bovine coronavirus were detected by double immunodiffusion (DID), neutralization of infectivity, indirect immunofluorescence, and immune electron microscopy. Human sera reacting in the DID test neutralized the infectivity of the bovine coronaviruses to indices of 2.5 to $>5$. Nineteen of 40 DID-negative, heat-inactivated sera had neutralizing indices of 1 to 3.0. Human serum with neutralizing and DID antibodies produced juxtanuclear and cytoplasmic fluorescence identical to that of bovine immune serum in cells infected with the bovine coronavirus. Antibodies in human and bovine sera interacted with the peplomeres of the bovine coronavirus, matting and bridging them, when present in excess, and facilitated formation of large viral aggregates when present in equivalent concentrations. Complement added to the virus-antibody complexes did not alter specifically the morphology of single, antibody-laden viral particles or viral particles in aggregates. Evidence of the transmission of coronavirus from experimentally inoculated calves to man, with ensuing gastroenteritis, was found by electron microscopic tracing of the coronavirus and its virus-antibody complexes.
\end{abstract}

\section{Introduction}

Coronaviruses are an important cause of enteritis and diarrhea in piglets, calves, rodents, and other animal species [11]. Intestinal infections of man with cornaviruses were demonstrated repeatedly by electron microscopy, but the significance of this infection as a cause of human enteric disease remains unsettled [ $1,2,16]$. Sharpe and Mebus [17] detected antibodies neutralizing infectivity of an enteropathogenic bovine coronavirus in sera of human subjects. Subsequently, antigenic relationships were found by direct and indirect immunofluorescence between the human coronavirus strain $0 \mathrm{C4} 3$, an enteropathogenic bovine coronavirus, the type 3 mouse hepatitis virus, and the $67 \mathrm{~N}$ hemagglutinating encephalomyelitis virus of swine [13]. Kaye and coworkers postulated that the occurrence of antibodies to $67 \mathrm{~N}$ in human sera may derive from heterologous antibody response during naturally occurring $0 \mathrm{C} 43$ infections [9]. 
Since human subjects may be exposed to enteropathogenic bovine coronavirus while caring for diarrheic calves, we investigated the reactivity of antibodies in human sera with antigens of an enteropathogenic bovine coronavirus. This report demonstrates evidence of antibodies against a bovine coronavirus in human sera that neutralized infectivity at a surprisingly high frequency, and it details the interactions of these antibodies with infected cells and viral structures.

\section{Materials and Methods}

\section{Coronavirus Strains Used}

The enteropathogenic bovine coronavirus strain L9 was used. It was originally isolated in bovine fetal kidney (BFK) cells from diarrhea fluid of a calf with enteritis [12]. It was adapted to bovine fetal thyroid (BFTy) cells for our investigations [18,19]. Diarrhea fluid (10/26) was also available from a human subject who developed gastroenteritis while caring for calves experimentally infected with the bovine coronavirus strain LY-138 $[4,5]$. This sample was collected on the fourth day after diarrhea began. The virus was partly purified from the human diarrhea fluid by differential and densitygradient centrifugation in sucrose, as described previously [5].

\section{Serum Samples Tested}

One hundred serum samples from a blood bank (kindly provided by Dr. H. Krauss); 36 sera from diagnostic admissions to the clinics of the Justus-Liebig-University, Giessen; (kindly provided by Dr. W. Willems) as well as 26 sera from students of a virology course, and 8 sera from laboratory workers in the Department of Microbiology at Colorado State University, Fort Collins, were tested by DID. Several high-titer bovine sera from calves with experimentally induced and naturally occurring coronavirus infection also were used [18].

\section{Double Immunodiffusion}

The micromethod of Crowle [3] was slightly modified and applied in the DID test. The reaction substrate, $1.2 \%$ agarose in a $0.9 \% \mathrm{NaCl}$ solution, was applied to precoated, $0.5-\mathrm{mm}$ thick glass slides. Plastic templates with one central well and 6 peripheral wells having diameters of $3.75 \mathrm{~mm}$ and spaced $8.5 \mathrm{~mm}$ appart were placed onto the agarose surface. Antigens and antisera were added to the wells in volumes of $25 \lambda$. The diffusion reaction proceeded for 2 days at room temperature in a humidified plastic container. The templates were removed, and the reaction slides were washed in saline for 24-36 hs. The agarose layer was then covered with filter paper and dried in a stream of warm air. The dried preparations were stained with $0.25 \%$ Coomassie brilliant blue, then destained with methanol-acetic acid-water $(5: 1: 5)$.

\section{Preparation of DID Antigen}

An alkaline extract of L9-infected BFTy cells was used as antigen [18]. Serum-free, L9-infected BFTy cells were scraped from the growth surface into the medium after cytopathic changes had developed. This suspension was centrifuged for $20 \mathrm{~min}$ at 
$10,000 \times \mathrm{g}$ at $5^{\circ} \mathrm{C}$. The cell sediment was suspended in $0.1 \mathrm{M}$ tris-barbital buffer (pH 8.6), disrupted with three short ultrasound treatments, then left in the refrigerator for 1 to $2 \mathrm{~h}$. The extracted antigen preparation was then centrifuged again, as described above. The supernatant fluid was concentrated to a protein content of $2-3$ $\mathrm{mg} / \mathrm{ml}$ by vacuum dialysis against tris-barbital buffer. Control antigens were prepared from uninfected BFTy cells by identical procedures.

\section{Microneutralization Test}

Constant 1:10 dilutions of serum that had been inactivated at $56^{\circ} \mathrm{C}$ for $30 \mathrm{~min}$ were mixed in amounts of $0.025 \mathrm{ml}$ with equal volumes of serial 10 -fold dilutions of $\mathrm{L} 9$ virus in Falcon microtest Il plates [18]. Four replicates were used, and the serumvirus mixtures were allowed to react for $1 \mathrm{~h}$ at room temperature before 50-100,00 BFTy cells in a volume of $0.05 \mathrm{ml}$ were added to each well. The cytopathic changes were scored after 6 days. The difference in infectivity between virus controls and the serum-virus mixtures, calculated according to the method of Reed and Muench [15], gave the neutralization index of a given serum.

\section{Indirect Immunofluorescence (IFA)}

The antigen consisted of L9-infected BFTy cells, which were fixed in cold paraformaldehyde as soon as clearly distinguishable cy topathic changes were evident. Sera free of, or positive for, antibodies against bovine coronavirus from calves and three human subjects were tested in dilutions of from $1: 10$ to $1: 320$ in the test. Fluoresceinisothiocyanate (FITC)-labeled antiserum against human or bovine IgG was used to trace binding of antibodies to coronavirus antigens in infected cells. Uninfected BFTy cells and normal sera served as controls.

\section{Immune Electron Microscopy (IEM)}

The interaction of antibodies in bovine $([13], 1745)$ and in human sera $(1255,1334$, 1339 ) with virions of coronavirus strain L9 was studied by IEM $(7,10)$. These tests were done with heat-inactivated sera diluted $1: 10,1: 20,1: 40$, and $1: 80$. The sera were tested against BFTy-propagated L9 virus and virus from human diarrhea (10/26). Cell culture fluid of L9-infected BFTy cells was centrifuged at $10,000 \times \mathrm{g}$ for $20 \mathrm{~min}$ to settle cell debris. The supernatant fluid was mixed in $10 \lambda$ amounts with $5 \lambda$ of the respective serum dilutions and allowed to react for $45 \mathrm{~min}$ at room temperature. Supernatant fluid from similarly centrifuged human diarrhea fluid was treated identically. The serum-virus mixtures were placed in $10 \lambda$ amounts on gel consisting of $0.4 \%$ agarose and $0.4 \%$ agar in barbital buffer of $\mathrm{pH} 8.2$ in $60-\mathrm{mm}$ Petri dishes. The plates were kept at $37^{\circ} \mathrm{C}$ for $30 \mathrm{~min}$ before the samples were applied. Formvar carbon-coated grids were placed onto the specimen drops on the agar surface. When the samples were absorbed, the grids were removed and negatively stained with $1.5 \%$ phosphotungstic acid for examination with an $\mathrm{HU}-12$ Hitachi electron microscope [4].

For assessing the effect of complement on the virus-antibody interaction, guinea pig complement at a 1:30 dilution was added in $5 \lambda$ amounts to serum dilution-L9 virus mixtures, as described above. This reaction mixture was incubated for $30 \mathrm{~min}$ 
at $37^{\circ} \mathrm{C}$. Complement, normal serum, and virus controls were included. These preparations were then processed as mentioned above for electron microscopic examination.

\section{Results}

Reactivity of Antibodies in Human Sera witb Antigens of Bovine Coronavirus $L 9$ in the DID Test

Serum samples from each of the 4 groups of human subjects tested reacted in the DID test with the antigen extracted from bovine coronavirus L9-infected cells. The blood bank samples had the lowest incidence, $7 \%$; whereas $25 \%$ of the clinic patients had DID antibodies (Table 1). These two serum groups were from Germany. The serum group from students, with 8 of 26 positive, and the serum group from laboratory work-

Table 1. Frequency of DID antibodies in human sera against bovine coronavirus L9

\begin{tabular}{lccc}
\hline & Number positive per & \multicolumn{2}{c}{ Number with $\times$ bands } \\
& total tested & 1 & 2 \\
\hline Blood bank samples & $7 / 100$ & 7 & 0 \\
Clinical samples & $9 / 36$ & 7 & 2 \\
Student samples & $8 / 26$ & 5 & 3 \\
Laboratory personnel samples & $4 / 8$ & 2 & 2 \\
Total & $28 / 170$ & 21 & 7 \\
\hline
\end{tabular}

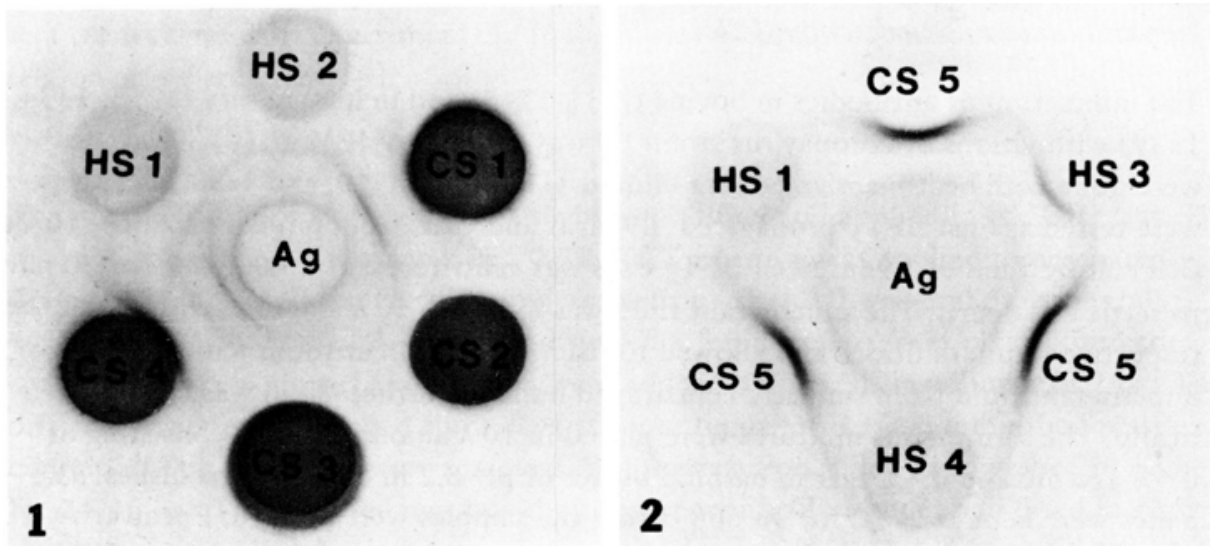

Fig. 1. Microimmunodiffusion reaction with bovine coronavirus $\mathrm{L} 9$ antigen $(A g)$ in center well and positive calf sera $\operatorname{CS} 1$ and $\operatorname{CS~} 4$, negative calf sera $\operatorname{CS} 2$ and $C S 3$, and the two positive human sera HS 1 and HS 2 in peripheral wells; $2 \mathrm{X}$

Fig. 2. Microimmunodiffusion reactions with bovine coronavirus $L 9$ antigen $(A g)$ in center well and positive bovine serum 1745 (CS S) alternating with 3 human sera that induce two bands (HS 3 ) and one band $(H S 1,4)$ identical to bands of positive calf serum in peripheral wells; $2 \mathrm{X}$ 
ers, with 4 of 8 positive, were from Colorado. Only one of the four laboratory workers had previously worked with bovine coronaviruses. The majority of the positive serum samples produced two bands with L9 antigens. Lines of identity were formed when the positive human samples were alternated with positive bovine sera (Figs. 1;2). These sera did not react with normal cell extracts.

\section{Correlation between DID and Neutralizing Antibodies in Human Sera}

The serum samples reacting in the DID test all neutralized the infectivity of bovine coronavirus $\mathrm{L} 9$, having neutralizing indices of 2.5 to more than 5 (Table 2). Forty serum samples that did not react in the DID test were assayed for neutralizing activity. Twenty one did not neutralize and 19 had an index of 1 to 3 . The neutralization test thus detected 19 of 28 subjects with antibodies in the blood bank group 16 of 27 in the clinic patient group. Accordingly, a relatively high proportion in human subjects have antibodies that neutralize the bovine coronavirus.

Table 2. Comparison of antibodies in human serum reacting with bovine coronavirus $L 9$ in immunodiffusion and neutralization of infectivity

\begin{tabular}{llllllll}
\hline \multirow{2}{*}{ Serum group } & & \multicolumn{6}{c}{ Number with neutralizing index of } \\
\cline { 5 - 8 } & $\begin{array}{l}\text { DID } \\
\text { reaction }\end{array}$ & $\begin{array}{l}\text { Number } \\
\text { tested }\end{array}$ & $0-1$ & $1-2$ & $2-3$ & $3-4$ & $4-5$ \\
Blood bank samples & + & 7 & 0 & 0 & 2 & 3 & 2 \\
& - & 21 & 9 & 9 & 3 & 0 & 0 \\
Clinical samples & + & 8 & 0 & 0 & 4 & 2 & 2 \\
& - & 19 & 12 & 7 & 0 & 0 & 0 \\
\hline
\end{tabular}

\section{Immunofluorescent Reaction of Human Sera with L9 Virus}

Human sera 1255, 1334, and 1339 were titered by indirect immunofluorescence, and the fluorescence pattern and titers were compared with bovine sera 13 and 1745 in BFTy cells infected with $\mathrm{L} 9$ coronavirus. Brilliant cytoplasmic fluorescence was observed with human serum having a titer of 20 . The bovine serum samples had titers of 40 (Table 3). Some individual cells had more intense juxtanuclear staining with both types of serum. The nuclei did not stain, nor did these sera react with uninfected cells (Figs. 3,4). Bovine and human sera not reacting in the DID test or neutralization test stained neither infected nor uninfected BFTy cells at dilutions of $1: 10$.

\section{Morphology of Virus-Antibody Complexes in IEM Investigations}

The interaction of antibodies against bovine coronavirus L9 in selected human and bovine sera was also compared by IEM. The serological activities of the sera used are given in Table 3 . When present in excess, antibodies in both human and bovine sera matted or bridged the peplomers of the L9 coronavirus (Fig. 5). Such viral particles remained single or in relatively small aggregates, but not all viral particles in a field 
Table 3. Interaction of selected human and bovine sera with bovine coronavirus $L 9$ as revealed by electron microscopy

\begin{tabular}{|c|c|c|c|c|c|c|}
\hline \multirow[b]{2}{*}{ Serum } & \multicolumn{3}{|c|}{ Human } & \multicolumn{3}{|c|}{ Bovine } \\
\hline & 1255 & 1334 & 1339 & 13 & 1745 & $\mathrm{NC}^{\mathrm{a}}$ \\
\hline DID reaction & + & + & + & + & + & -- \\
\hline Neutralization index & 3.5 & 2.5 & 3.0 & 3.5 & 4.0 & 0 \\
\hline Immunofluorescene & $20^{b}$ & 20 & 20 & 40 & 40 & $<10$ \\
\hline $\begin{array}{l}\text { Dilution causing } \\
\text { matting of viral } \\
\text { peplomers }\end{array}$ & 20 & 10 & 10 & 20 & 10 & $<10$ \\
\hline $\begin{array}{l}\text { Dilution forming } \\
\text { large virus } \\
\text { aggregates }\end{array}$ & 40 & 40 & 40 & 40 & 40 & $<10$ \\
\hline
\end{tabular}

$a$ = normal calf serum; $b=$ titer of serum in indirect test
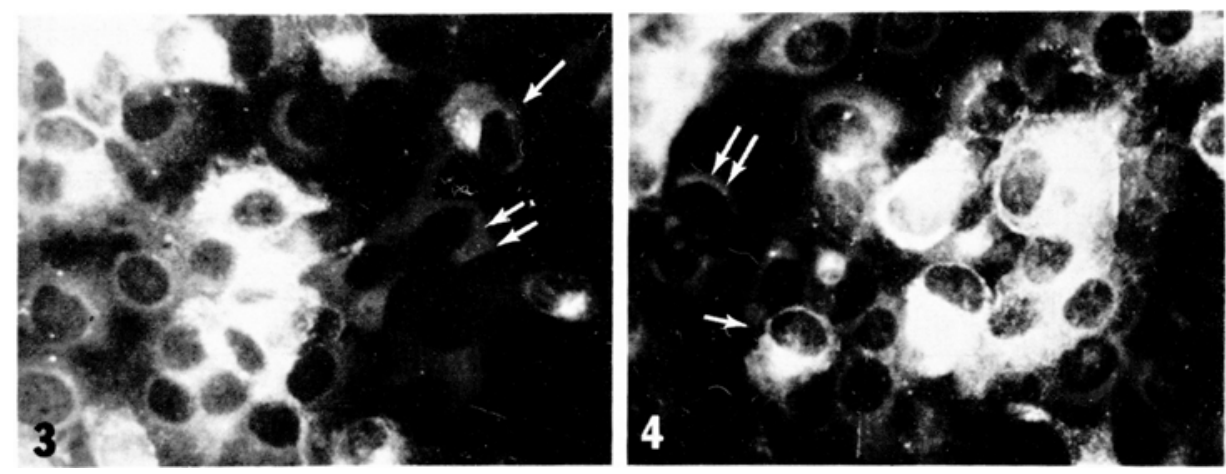

Fig. 3. Indirect immunofluorescent reaction with $1: 40$ dilution of calf serum 1745 and BFTy cells infected with bovine coronavirus L9. Notice juxtanuclear (one arrow) and complete cytoplasmic fluorescene. Uninfected cells do not fluoresce ( $t w o$ arrows)

Fig. 4. Indirect immunofluorescent reaction with 1:20 dilution of human serum 1255 and BFTy cells infected with bovine coronavirus L9. The fluorescene pattern is identical to that in Fig. 3

were matted. The matting reaction on the peplomeres was most readily seen on virus particles that were flat and partly covered with stain. At equilibrium concentrations of antibodies and virus particles, large viral aggregates formed with human as well as bovine sera (Fig. 6). Virtually no single particles remained in these preparations. It was difficult to identify antibody molecules bridging virus particles in such aggregates.

When complement was added to the antiserum dilutions or after antibodies had interacted with the virions, matted particles also were seen, but the viral aggregates were smaller. Viral membrane pitting or other changes were not observed in viral particles excluding stain. Compared with normal virus controls, flat, stain-covered viral particles had increased structural damage in complement-treated samples. However, 
these changes also were observed in the incubated virus controls, as well as in the incubated virus-serum and virus-complement controls.

\section{Evidence for Transmission of Coronavirus from Calves to Man}

During pathogenetic studies of coronavirus enteritis, one investigator, while handling calves inoculated orally with coronavirus strain LY-138 [4], developed gastroenteritis with diarrhea that lasted 4 days. One diarrhea sample was collected for viral examination. Virus could not be cultivated from this sample. This strain was maintained by oral inoculation and intestinal passage in calves. Electron microscopic examination of differentially centrifuged diarrhea samples contained round or pleomorphic enveloped viral particles 80 to $130 \mu \mathrm{m}$ in diameter and with surface projections characteristic of coronaviruses. These viral structures were flat and covered with stain. Morphologic

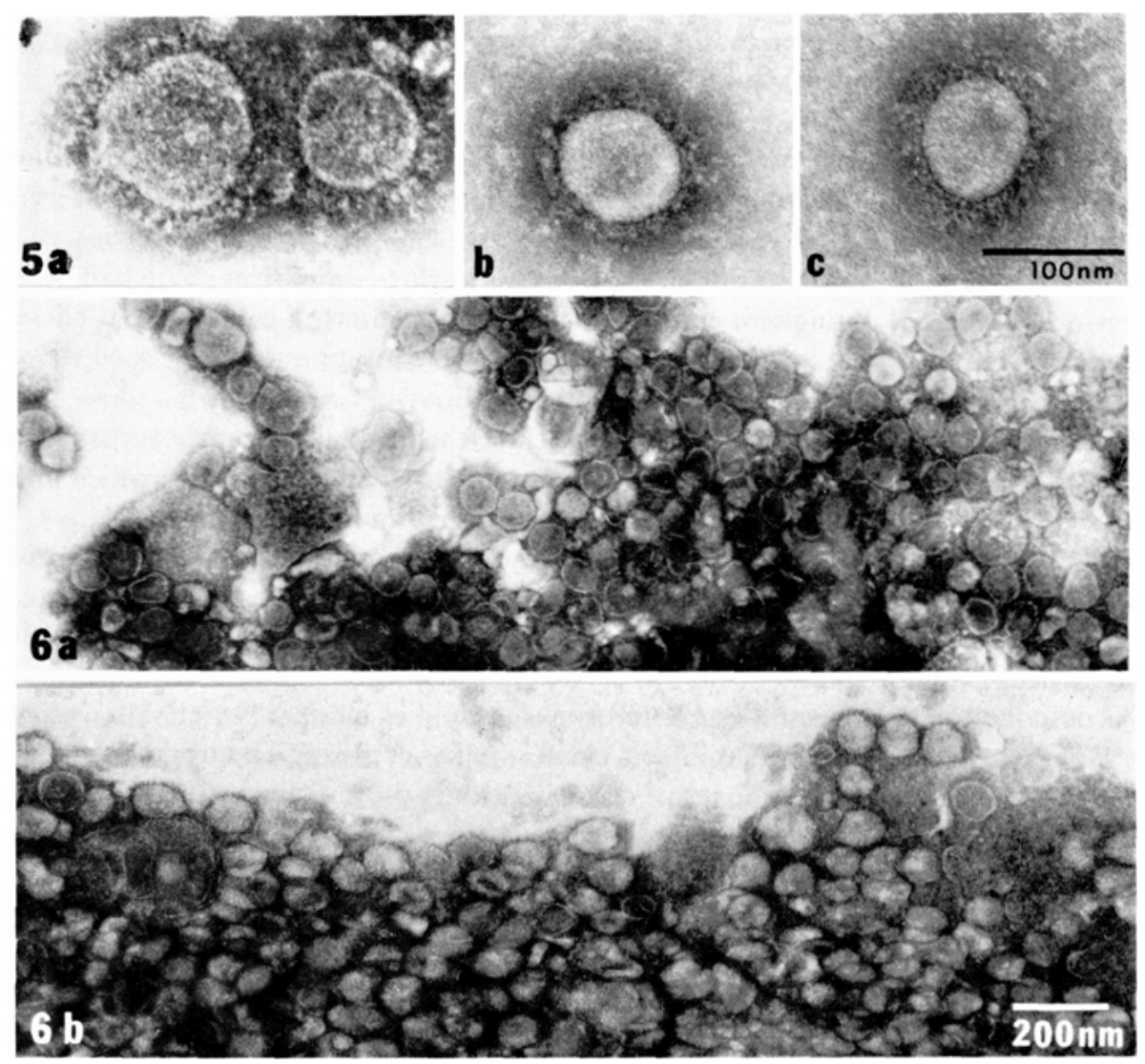

Fig. 5. Matting and bridging of peplomeres of $\mathrm{L9}$ bovine coronavirions with antibodies of (a) bovine serum 1745 (b,c) human serum 1255 in immune electronmicroscopic analysis

Fig. 6. Margin of bovine coronaviral aggregate induced by (a) bovine serum 1745 and (b) human serum 1255 after interaction with medium from L9-infected BFTy cells 
evidence for other types of viruses was not found. Bovine serum 1745 and human serum 1334 induced matting of surface projections and aggregations of viral particles. A serum sample collected from this subject a year before this episode did not react in the DID test, but one collected thereafter induced one precipitin band in the DID test and had a neutralization index of 3 .

\section{Discussion}

This limited serological survey demonstrated that antibodies against an enteropathogenic bovine coronavirus occur in human sera obtained from subjects in Germany and the United States. These sera had antibodies that neutralized the infectivity of the bovine coronavirus, but they also functioned in the DID, IEM, and IFA reactions. This finding confirms the observation of Sharpee and Mebus [17], who previously found that antibodies in human serum neutralized a bovine coronavirus. An antigenic relationship had also been demonstrated, by direct or indirect immunofluorescence, between human coronavirus represented by the organ culture strain $0 \mathrm{C} 43$ the porcine hemagglutinating encephalomyelitis virus $67 \mathrm{~N}$ mouse hepatitis coronavirus type 3 and a bovine coronavirus [13].

It was surprising to us how frequently these cross-reacting antibodies can be found in human sera. Even so-called normal sera obtained from a blood bank had $7 \%$ that were positive in the DID test, and a still higher percentage had neutralizing antibodies. A similarly high frequency of antibodies against this bovine coronavirus strain had been previously detected during sero-epidemiological investigations of cattle $[5,18]$. These results demonstrate that infections with bovine coronavirus or a closely related virus are widespread in human and cattle populations.

The different serological methods used exclude the possibility that the cross-reactions found were due to the presence of nonspecific inhibitors. Such inhibitors, which influence hemagglutination by coronaviruses, are known to occur in human serum [6,8]. Similarly, the participation of so-called heterotypic antibodies on the serological crossreactions $[9,14]$ can be excluded, since all serum samples tested were heat-inactivated. Furthermore, there was no evidence in the electron microscopic pictures that complement changes the morphology of virus particles in virus-antibody complexes which was described to be the case when heterotypic antibodies interact [14].

Whether the same virus strain infects man as well as cattle, or whether the demontion of antibodies is merely the result of similarities in the antigenic structure in two different species-specific virus strains is not yet known. The immune electron microscopic findings and the results of the neutralization tests suggest that the reactive antigen is associated with the glycoprotein peplomeres. From the murine coronavirus A59 it is known that the glycoprotein E2 induces the formation of neutralizing antibodies [20]. The general experience that viral glycoproteins are strain-specific antigens could favor the assumption that the same coronavirus strain, which has a stable antigenic structure [18], may infect either species. Accordingly, the extent of the antigenic relationship between $\mathrm{OC} 43$ and the bovine coronavirus has to be defined further. It is of interest that calf sera commercially available for cell culture contained antibodies having high neutralizing activity for the L9 strain [18]. Such calf serum specifically neutralized the human coronavirus strain $0 \mathrm{C} 43$ [6]. 
The significance of bovine coronavirus as a causative agent for a human disease cannot be assessed at the present time. One should be aware of the possibility that the infection may become of clinical importance in rural areas. Our findings that the bovine coronavirus LY-138 was transmitted from calves to man, resulting in gastroenteritis with diarrhea, seems to be especially relevant. The potential danger that bovine coronavirus could infect man should be kept in mind when calves affected with coronaviral enteritis are handled.

Acknowledgments. These investigations were made possible through an Alexander von Humboldt Award to J. Storz for a year of research at the Institut für Virologie, Justus-Liebig-Universität, Giessen, Germany. Support for the investigations also came from the Deutsche Forschungsgemeinschaft (Sonderforschungsbereich 47), from the Regional Project W-112, and from Special Research Grant 02-105, Science and Education Administration, United States Department of Agriculture. We thank Eva Kroell, Deryl Keney, and Mary Hegedus for skillful assistance.

\section{References}

1. Caul EO, Clarke SKR (1975) Coronavirus propagated from patients with nonbacterial gastroenteritis. Lancet II:953-954

2. Caul EO, Paver WK, Clarke SKR (1975) Coronavirus particles in faeces from patients with gastroenteritis. Lancet I: 1192-1193

3. Crowle AJ (1959) A simplified mirco-double diffusion agar precipitin technique. J Lab Clin Med 52:784-787

4. Doughri AM, Storz J (1977) Light and ultrastructural pathologic changes in intestinal coronavirus infection of newborn calves. Zentralbl Vet Med (B) 24 : $367-387$

5. Hajer I, Storz J (1978) Antigens of bovine coronavirus strain LY-138 and their diagnostic properties. Am J Vet Res 39:441-444

6. Gerna G, Cattaneo E, Cereda PM, Garcia Revelo M, Achilli G (1980) Human coronavirus $O C 43$ inhibititor and neutralizing antibody by a new plaque reduction assay: Proc Soc Exp Biol Med 163:360-366

7. Kapikian AZ, James HD, Kelly SJ, Vaugh AL (1973) Detection of coronavirus strain 692 by immunoelectron microscopy. Infect Immun 7:111-116

8. Hovi $\mathrm{T}$ (1978) Nonspecific inhibitors of coronavirus $0 \mathrm{C} 43$ haemagglutination in human sera. Med Microbiol Immunol 166:173-176

9. Kaye HS, Yarbrough WB, Reed CJ, Harrison AK (1977) Antigenic relationship between human coronavirus strain $0 \mathrm{C} 43$ and hemagglutinating encephalomyelitis virus strain $67 \mathrm{~N}$ of swine: Antibody responses in human and animal sera. J Inf Dis 135:201-209

10. McIntosh K, Kapikian AZ, Hardison KA, Hartley JW, Chanock RM (1969) Antigenic relationship among the coronaviruses of man and between human and animal coronaviruses. J Immunol 102:1109-1118

11. McIntosh K (1974) Coronaviruses: A comparative review. Current Topics Microbiol Immunol 63:85-129 
12. Mebus CA, Stair EL, Rhodes MB, Twiehaus MJ (1973) Neonatal calf diarrhea: Propagation, attenuation, and characteristics of a coronavirus-like agent. Am J Vet Res 34:145-150

13. Pedersen NC, Ward J, Mengeling WL (1978) Antigenic relationship of the feline infectious peritonitis virus to coronaviruses of other species. Arch Virol 58:45-53

14. Pike BV, Garwes DJ (1979) The neutralization of transmissible gastroenteritis virus by normal heterotypic serum. J Gen Virol 42:279-287

15. Reed LJ, Muench H (1938) A simple method of estimating fifty percent endpoints. Am J Hyg 27:493 -498

16. Schnagl RD, Holmes IH, Mackay-Scollay EM (1978) Coronavirus-like particles in Aboriginals and non-Aboriginals in Western Australia. Med J Aust 1:307-310

17. Sharpee R, Mebus CA (1975) Letter to the editor. Lancet I:639

18. Storz J, Rott R (1980) Über die Verbreitung der Coronavirusinfektion bei Rindern in ausgewählten Gebieten Deutschlands: Antikörpernachweis durch Mikroimmundiffusion und Neutralisation. Dtsch Tierärztl Wochenschr 87:252-254 (1980)

19. Storz J, Rott R, Kaluza G (in press) Enhancement of plaque formation and cell fusion of an enteropathogenic coronavirus by trypsin treatment. Infect Immun

20. Sturman LS, Holmes KV (1977) Characterization of a coronavirus. 11. Glycoproteins of the viral envelope: Tryptic peptide analysis. Virol 77:650-660 